\title{
Finding alternatives to disability benefit receipt
}

\author{
Gina Livermore ${ }^{1}$, David Wittenburg ${ }^{2^{*}}$ and David Neumark ${ }^{3,4}$
}

\author{
* Correspondence: dwittenburg@ \\ mathematica-mpr.com \\ ${ }^{2} 600$ Alexander Park, Suite 100 \\ Princeton, NJ 08540, USA \\ Full list of author information is \\ available at the end of the article
}

\begin{abstract}
This introduction offers a context for the articles in this thematic series by providing an overview of the programs that provide cash and in-kind supports to people with disabilities in the United States, summarizes the increasing reliance on these programs, and describes the challenges associated with reducing dependency on these programs. It then briefly discusses the articles in this thematic series in light of these issues.

JEL codes: $\mathrm{H} 5, \mathrm{I3}, \mathrm{J} 2, \mathrm{~J} 14$

Keywords: Disability; Employment; Social Security Disability Insurance
\end{abstract}

\section{倠

\section{Introduction}

Over the past three decades in the United States, there have been sharp increases in benefit receipt and large declines in employment and income of people with disabilities relative to their counterparts without disabilities. An increasing share of people with disabilities receives cash supports from the Social Security Administration's (SSA) disability programs, which include Social Security Disability Insurance (SSDI) and Supplemental Security Income (SSI). This trend has heightened policy interest in finding alternatives to disability benefit receipt-including employment-to promote economic well-being of people with disabilities and to alleviate fiscal pressures on the SSA trust fund and federal budget. Finding alternatives to benefit receipt is challenging, however. Personal barriers to employment, work disincentives inherent in the SSI and SSDI programs, a fragmented and poorly coordinated system of supports, and limited means by which early intervention might occur contribute to the difficulty facing policy makers in developing the means to reduce disability expenditures.

This thematic series of IZA Journal of Labor Policy presents a set of articles that explores means to promote employment and/or delay benefit receipt among people with disabilities prior to or after their entry into SSA disability programs. It includes studies of promising interventions and evidence regarding the efficacy of existing supports. Additionally, it draws on lessons from other countries that could inform policies and programs in the United States.

This introduction offers a context for the articles in this thematic series by providing an overview of the programs that provide cash and in-kind supports to people with disabilities in the United States, summarizes the increasing reliance on these programs, and describes the challenges associated with reducing dependency on these programs. It then briefly discusses the articles in this thematic series in light of these issues.

(c) 2014 Livermore et al.; licensee Springer. This is an Open Access article distributed under the terms of the Creative Commons Attribution License (http://creativecommons.org/licenses/by/4.0), which permits unrestricted use, distribution, and reproduction in any medium, provided the original work is properly credited. 


\section{Increasing reliance on program supports and diminishing employment rates}

The SSI and SSDI programs are designed to provide income support to those with significant disabilities who are unable to work at substantial levels. To qualify for either program, an applicant must demonstrate an inability to engage in substantial gainful activity (SGA) due to a medically determinable impairment that is expected to last at least 12 months or to result in death. In 2014, SSA considers earnings above $\$ 1,070$ per month as SGA for most applicants. SSDI eligibility is also contingent on having a sufficient number of recent and lifetime quarters of Social Security-covered employment. The SSDI benefit level is based on past earnings; individuals with higher lifetime earnings are eligible for higher SSDI benefits. SSI is a means-tested program, with eligibility subject to strict income and asset limits. The SSI payment is based on the individual's monthly income and living arrangement. Individuals may qualify for both programs if their incomes (including SSDI benefits) and assets are low enough to meet the SSI income limits.

Most SSDI and SSI beneficiaries qualify for Medicare and Medicaid, respectively. Although there are eligibility and health coverage differences between Medicare and Medicaid, both offset potentially expensive medical care costs and, therefore, may be extremely valuable to people with disabilities. SSI recipients (in most states) are categorically eligible for Medicaid; SSDI beneficiaries become eligible for Medicare after a two-year waiting period following SSDI eligibility.

A major policy challenge is that the caseloads and expenditures of these programs have expanded substantially over the past several decades, with substantial recent growth that has put stress on the SSDI and Medicare trust funds. SSI program expenditures, funded through general revenues, have also increased substantially. Federal expenditures to support working-age people with disabilities across all programs (estimated at $\$ 357$ billion in 2008 , including approximately $\$ 170$ billion each on income maintenance and health care expenditures) account for a nontrivial and growing share of all federal expenditures. They represented 12.0 percent of all federal outlays in fiscal year 2008, up from 11.3 percent just six years earlier (Livermore et al. 2011). In 2009, 65 percent of all working-age people with disabilities received benefits from at least one of 15 major public income, food, health insurance, and housing support programs, compared with 17 percent of their nondisabled counterparts (Houtenville and Brucker 2013). Because of the large program growth, SSA actuaries project that the SSDI Trust Fund will be exhausted in 2016 (Social Security and Medicare Boards of Trustees 2013). Much of the growth in the SSDI program stems from the growth and aging of the working-age population, growth in women's labor force participation, and the rise in the Social Security full retirement age. Although researchers generally agree that a substantial portion of the SSDI program growth stems from demographic changes (Ruffing 2014), they disagree on the extent to which other, more difficult to quantify factors have played a role in SSDI program growth, including legislative changes that expanded eligibility for SSDI, increases in the relative generosity of SSDI benefits, the changing nature of work, and changes in access to health insurance.

At the same time spending on programs that target working-age people with disabilities has been increasing, the employment and household income of people with disabilities have steadily declined relative to their peers (Stapleton 2011; Weathers and Wittenburg 2009). From 1990 to 2012, the employment rate of working-age people with disabilities fell from 29 percent to 15 percent, whereas the rates for people without 
disabilities have remained fairly steady in the mid to high 70 percent range. Over the same period, median household income for people with disabilities fell from about 58 percent of that of their peers without disabilities, to 50 percent (Nazarov and Lee 2012).

The idea that people with significant disabilities can work and contribute to their own support has been a part of the independent living movement for over thirty years (Stapleton et al. 2006), though actual spending on employment and rehabilitation supports represent a very small share of all public expenditures on working-age people with disabilities. Livermore et al. (2011) estimate that just over 1 percent of all federal and state expenditures on programs for working-age people with disabilities in 2008 were for employment-related supports. State Vocational Rehabilitation (VR) programs provide the largest source of support for rehabilitation and employment services. The target population for VR services generally includes any individual who has a work limitation and who has the potential to benefit from VR services to become employed. However, VR agencies' ability to provide services to all eligible people with disabilities are often limited by funding availability. A state VR agency is required to implement an order of selection, whereby service priority is given to people with the most significant disabilities, such as those who receive SSDI and SSI benefits, when it anticipates that it will not have sufficient fiscal and/or personnel resources to fully serve all eligible individuals (Hyde and Honeycutt 2014).

Increasing disability program expenditures and declining employment rates of people with disabilities are not unique to the United States. Many have pointed to fundamental problems with the structure of disability support systems as the source of the current fiscal challenges and limited employment of working-age people with disabilities (World Health Organization and the World Bank 2011; Organisation for Economic Co-operation and Development 2010; Stapleton et al. 2006; United States Government Accountability Office 2005, 2008; Social Security Advisory Board 2006; Mashaw and Reno 1996). We describe some of the challenges below in addressing both the expansion in disability program spending and the decline in employment rates.

\section{Challenges to reversing current trends}

People with disabilities, and the public and private programs and policies that serve them, face a variety of challenges in promoting employment and reducing reliance on public cash and health support programs. Because most who qualify for SSI and SSDI are also eligible for Medicaid and/or Medicare, potential workers with disabilities must weigh the benefits of employment against the combined benefits of public cash and health supports, which can be substantial, especially for those with costly health care needs. These challenges include personal barriers to employment, work disincentives inherent in the SSI and SSDI programs, a fragmented and poorly coordinated system of supports, and limited means by which early intervention might occur.

\section{Barriers to employment}

In addition to experiencing poor health and functional limitations that might inhibit work, people with disabilities frequently encounter a long list of potential barriers to employment that contribute to their low employment rates and generally poor employment outcomes. Common employment barriers reported by SSI and SSDI beneficiaries who indicate that they want to work include fear of job failure, 
fear of benefit loss, lack of job qualifications, lack of reliable transportation, inaccessible or inflexible work environments, and negative employer perceptions of disability (Livermore et al. 2009).

\section{Work disincentives}

Public disability benefits are generally available only to those who have been deemed unable to engage in SGA because of long-lasting, medically determinable conditions, via successful application for SSDI or SSI. This eligibility concept has been in place with little change since SSDI's inception in 1956, even as changes in the nature of work and advances in medicine and technology have made it possible for many individuals with such conditions to be productive and self-sufficient. The resulting policy structure discourages work, as does the treatment of earnings in the assessment of the ongoing eligibility of those receiving SSI and SSDI benefits. Because health insurance coverage is very important to most people with significant chronic conditions or disabilities, the inability to obtain private health insurance might induce some individuals with disabilities who could continue working to stop doing so in order to obtain public health insurance coverage by means of eligibility for SSI or SSDI. Greater access to private coverage through the newly implemented provisions of the Affordable Care Act (ACA) might reduce the employment disincentives associated with SSI and SSDI, but the effects of the ACA on the employment of people with disabilities remain to be seen. Other ACA provisions may shift some working people with disabilities receiving Medicaid through avenues other than SSI (for example, through Medicaid buy-in programs) to private plans that offer a much less comprehensive package of benefits. This would occur if states choose to eliminate or restrict optional avenues to Medicaid eligibility that allow higher income eligibility levels. This might create incentives for some individuals to limit their earnings in order to retain Medicaid eligibility.

\section{Program fragmentation and conflicting incentives}

A support system that involves multiple agencies and levels of government creates pervasive inefficiencies and misaligned incentives. As the U.S. Government Accountability Office (2005) has documented, a plethora of state and federal disability support programs create service overlaps and gaps, and conflicting objectives. Over 21 federal agencies and about 190 programs provide assistance to people with disabilities in the United States, including cash, health, rehabilitation, employment, and other supports. Approximately half of these programs are dedicated specifically to serving people with disabilities, whereas the remaining programs are available to those both with and without disabilities. In addition, more than 10 congressional committees had jurisdiction over the 21 federal agencies providing supports.

Fragmentation of the existing system leads to misaligned program goals and can create incentives away from promoting employment for people with disabilities. For example, state VR agencies have incentives to help non-beneficiary clients obtain SSDI and SSI benefits, both to help improve the short-term economic well-being of their clients and so that the agencies will be eligible for payments from SSA when the clients eventually return to work. Coordination of Medicare and Medicaid in the care of dualeligible beneficiaries would reduce the incentives for one payer to push costs onto the other (states to the federal government or vice versa) and might result in more efficient 
care being provided to beneficiaries (Medicare Payment Advisory Commission 2010). The performance indicators used by the Department of Labor for services provided through American Job Centers (formerly known as One-Stop Career Centers) can discourage these centers from serving people with disabilities and create strong incentives for them to refer customers with disabilities to state VR programs. This can lead to inefficiencies because not all people with disabilities require the intensive services provided by VR, and in many states, there is a considerable wait to obtain VR services.

\section{Limited early intervention mechanisms}

It is widely recognized that the United States does not have a comprehensive system in place to help workers stay at or return to work after experiencing the onset of a significant medical condition (Mashaw and Reno 1996; Social Security Advisory Board 2006; National Council on Disability 2007; Ticket to Work and Work Incentives Advisory Panel 2007). Those with job-related disabilities and health conditions often receive support under workers' compensation. Private disability insurance companies often provide returnto-work services for those with such coverage. However, less than one-third of all US workers in private industry have access to such coverage (U.S. Department of Labor 2007). Workers without such coverage can potentially obtain help from their state VR agency, but given the priorities and limited funding of VR agencies, it might be difficult for individuals to receive VR services during the early stages of disability onset, while they are still working. Other public or private entities (such as the American Job Centers) might provide services, but there are few mechanisms and no comprehensive system in place to ensure that all workers and their employers receive employment-related assistance soon after the onset of a potentially disabling health condition.

\section{Existing evidence}

To address some of the employment-related challenges faced by beneficiaries, SSA has sponsored numerous demonstration projects. Several tests of employment-related innovations have used random assignment, including Project NetWork, the Mental Health Treatment Study, and Accelerated Benefits. Others have used non-experimental methods or a mixture of experimental and non-experimental methods: the State Partnership Initiative and the Ticket to Work evaluation are important examples. Other federal agencies have supported research on innovations to improve employment outcomes for this population and/or reduce reliance on public support, including the U.S. Departments of Education, Health and Human Services, and Labor. Examples include: the non-experimental evaluation by the Centers for Medicare \& Medicaid Services (CMS) of the Medicaid Buy-In, a Medicaid option designed to provide assured access to health insurance at an attractive cost to workers with disabilities (Gimm et al. 2009); the experimental Demonstration to Maintain Independence and Employment, a CMS initiative to provide integrated health and employment services to insured workers with disabilities, with the objective of helping them remain employed (Whalen et al. 2011); the nonexperimental evaluation of the U.S. Department of Labor's Disability Program Navigator, designed to make services at American Job Centers more accessible to those with disabilities (Livermore and Colman 2010); and the Department of Labor's Disability Employment Initiative, a quasi-experimental effort currently in progress to improve the efficacy of American Job Center services for people with disabilities. 
This large body of research has demonstrated the enormous difficulty of helping and encouraging people with chronic health conditions and disabilities to work and earn enough to become self-sufficient. In reviewing these demonstrations, Wittenburg et al. (2013) found that none had the potential to lead to substantial caseload reductions that could reverse program growth, though some targeted approaches appeared promising with respect to improving employment. In general, the interventions that demonstrated the most promising effects tended to provide customized supports to more narrowly targeted subgroups, in particular, younger persons and those with psychiatric impairments. The findings from Wittenburg et al. (2013) also highlighted the challenges that federal agencies face related to the work disincentives and program fragmentation issues noted above, which have likely limited the interventions' effects.

With respect to early intervention initiatives, there is evidence of a large window of opportunity to address the employment and health issues of working people with disabilities before they leave employment and get onto SSDI benefits. One study found that people who come onto SSDI are generally attached to the labor force and employed at the same rates as other working-age individuals during the period two to three years before they enter SSDI (Livermore et al. 2010), but during this period, a rather large percentage (41 percent) are experiencing limitations in their daily activities. If there were a means to identify and target services to these individuals before their limitations caused them to separate from their jobs, many might be delayed or prevented from entering SSDI. The same study found that 20 percent of new SSDI awardees had at least one prior SSDI application rejected. This group has strongly signaled that they are heading for SSDI entry; however, there is little in the public support system to help them return to work, even though it is highly likely they will eventually go onto SSDI.

Although the window of opportunity for intervening early appears large, developing early intervention services is difficult because of the work disincentives and program fragmentation issues noted above. Namely, a major challenge is identifying people who are candidates for early intervention so that these types of supports can be effectively tested. Evidence on the effectiveness of early intervention programs is limited. Numerous studies have examined the effectiveness of workers' compensation and private disability insurance services. Although many are methodologically weak or inconclusive, some rigorous studies have demonstrated that insurers and their vendors can be effective (McLaren et al. 2010; Habeck et al. 2008). There has been extensive research on the effectiveness of VR services, but no studies have examined their effectiveness as an early intervention for workers after disability onset.

\section{Articles in this thematic series}

The articles in this thematic series of the IZA Journal of Labor Policy provide new information about the factors affecting program growth and the potential for early intervention and employment support strategies to reduce reliance on public disability benefits. Four of the articles examine the factors that influence disability program participation and the role of policy in influencing outcomes. Burkhauser et al. (2014) draw on the disability program experiences from five Organisation for Economic Co-Operation and Development nations to identify lessons in reforming disability policy, concluding that the strongest strategies attempt to stem new beneficiary growth rather than promote exits by existing beneficiaries. Bound et al. (2014) present new estimates on the 
relationship between the expansion of SSDI eligibility requirements and the declining employment rates of working-age men with work limitations, showing that other factors explain much of the employment decline, such as shifts in labor demand for unskilled workers. Iyengar and Mastrobuoni (2014) also find strong evidence that shifts in labor demand affect disability program growth. The findings suggest that the effects were particularly strong in states where political interests might have directly influenced growth in disability caseloads. Finally, Coe et al. (2014) examine the individual experiences of people who had long wait times for SSDI benefits, showing that coping strategies, especially reliance on spousal employment and other sources of public support, are used both to help applicants during the wait time and to increase their probability of obtaining benefits.

The remaining four articles examine the potential for early intervention and rehabilitation supports to influence program and employment outcomes. Dean et al. (2014) and Hyde and Honeycutt (2014) find strong correlations between state VR processes and eventual decisions of VR clients to apply for disability benefits. Campolieti et al. (2014) find modest effects in Canada of VR services increasing disability program exits and increasing employment, although the benefits are concentrated in select groups, suggesting that it might be more cost-effective to target VR services more selectively. Finally, (Stapleton et al. 2014) find that return-to-work services available to people after they qualify for disability benefits through the SSA's Ticket to Work program had modest effects on service enrollment, but no effects on other outcomes, such as employment and SSDI program participation.

\section{Conclusions}

The articles in this series address diverse issues related to the challenges of reversing increasing reliance on disability programs. A recurring theme across the articles is the strong potential that more narrowly targeting supports to people with disabilities and significant health conditions before they apply for benefits has for reducing program growth. The cross-national lessons in Burkhauser et al. (2014) point to the relative effectiveness of targeting strategies aimed at new applicants, rather than later intervention supports to those already on the rolls. Their findings are reinforced by the findings of Dean et al. (2014) and Hyde and Honeycutt (2014), which suggest that people who receive substantive VR services are less likely to apply for SSDI benefits. The findings of Stapleton et al. (2014) and Campolieti et al. (2014) highlight the challenges of attempting to provide services for those who already receive disability benefits. As policymakers continue to wrestle with the fiscal issues associated with disability caseload growth, they might find solutions in early intervention approaches. Although the findings of these articles suggest that early intervention has potential to reduce program growth, they do not demonstrate which approaches would be most successful.

\section{Competing interests}

The IZA Journal of Labor Policy is committed to the IZA Guiding Principles of Research Integrity. The authors declare that they have observed these principles.

\section{Acknowledgements}

Preparation of this paper and this special journal thematic series was supported by the National Institute on Disability and Rehabilitation Research, U.S. Department of Education, through its Rehabilitation Research and Training Center on Employment Policy and Measurement grant to the University of New Hampshire Institute on Disability, under cooperative agreement H133B100030. The contents do not necessarily represent the policy of the U.S. Department of 
Education or any other federal agency (Education Department General Administrative Regulations, 75.620 [b]). The authors are solely responsible for all views expressed and any errors or omissions.

Responsible editor: Juan F Jimeno

\section{Author details}

${ }^{1}$ Mathematica Policy Research 1100, 1st Street NE 12th Floor, Washington, DC 20002, USA. ${ }^{2} 600$ Alexander Park, Suite 100, Princeton, NJ 08540, USA. ${ }^{3}$ Department of Economics University of California-Irvine, 3151 Social Science Plaza, Irvine, CA 92697-5100, USA. ${ }^{4}$ National Bureau of Economic Research and Institute for the Study of Labor (IZA).

Received: 30 May 2014 Accepted: 3 June 2014

Published: 07 Jul 2014

\section{References}

Board SSA (2006) Disability Decision Making: Data and Materials. Social Security Administration, Washington DC

Bound J, Lindner S, Waidmann T (2014) Reconciling Findings on the Employment Effect of Disability Insurance. IZA Journal of Labor Policy 3:11

Burkhauser RV, Daly MC, McVicar D, Wilkins R (2014) Disability benefit growth and disability reform in the US: lessons from other OECD nations. IZA J Labor Policy 3:4

Campolieti M, Gunderson MKL, Smith JA (2014) The effect of vocational rehabilitation on the employment outcomes of disability insurance beneficiaries: new evidence from Canada. IZA J Labor Policy 3:10

Coe NB, Lindner S, Wong K, Wu A (2014) How do people with disabilities cope while waiting for disability insurance benefits? IZA J Labor Policy 3:1

Commission MPA (2010) Report to Congress: Medicare Payment Policy. Medicare Payment Advisory Commission, Washington DC

Dean D, Pepper JV, Schmidt RM, Stern S (2014) State vocational rehabilitation programs and federal disability insurance: an analysis of Virginia's vocational rehabilitation program. IZA J Labor Policy 3:7

Gimm GW, Andrews KL, Schimmel JL, Ireys HT, Liu S (2009) Analysis of medical expenditures and service use of Medicaid buy-in participants, 2002-2005, final report. Mathematica Policy Research, Washington DC

Habeck R, Crockett S, Rachel C, Kregel J (2008) Organizational factors that facilitate successful job retention of employees with health impairments and disabilities. In: Wehman P, Kregel J, Brooke V (eds) Workplace supports and job retention: promoting an employer driven approach to employment of people with disabilities. Richmond, VA, pp 39-66

Houtenville AJ, Brucker DL (2013) Participation in safety-net programs and the utilization of employment services among working-age persons with disabilities. J Disabil Policy Stud, published online before print. http://dps.sagepub.com/content/early/recent. Accessed 20 February 2014

Hyde JS, Honeycutt T (2014) The Relationship Between Timely Delivery of Vocational Rehabilitation Services and Subsequent Federal Disability Benefit Application and Receipt. Policy, IZA Journal of Labor Policy forthcoming

lyengar R, Mastrobuoni G (2014) The Political Economy of the Disability Insurance: Theory and Evidence of Gubernatorial Learning. Policy, IZA Journal of Labor Policy forthcoming

Livermore G, Roche A, Prenovitz S (2009) SSI and DI Beneficiaries With Work-Related Goals and Expectations, Report no. 5. In: Work Activity and use of Employment Supports Under the Original Ticket to Work Regulations. Mathematica Policy Research, Washington DC

Livermore G, Stapleton DC, OToole M (2011) Health care costs are a key driver of growth in federal and state assistance to working-age people with disabilities. Health Aff 30(9):1664-1672

Livermore GA, Colman S (2010) Use of One-Stops by Social Security Disability Beneficiaries in Four States Implementing Disability Program Navigator Initiatives, Final Report. Mathematica Policy Research, Washington DC

Livermore GA, Stapleton DC, Claypool H (2010) Health care when workers need it most: before and after entry into the Social Security Disability Insurance Program. Inquiry 47(2):135-149

Mashaw JL, Reno VP (1996) Balancing Security and Opportunity: The Challenge of Disability Income Policy. National Academy of Social Insurance, Washington DC

McLaren CF, Reville RT, Seabury SA (2010) How Effective are Employer Return to Work Programs? Rand Center for Health and Safety in the Workplace. Santa Monica, CA

National Council on Disability (2007) Empowerment for Americans With Disabilities: Breaking Barriers to Careers and Full Employment. National Council on Disability, Washington DC

Nazarov Z, Lee CG (2012) Disability statistics from the Current Population Survey (CPS). Cornell University Rehabilitation Research and Training Center on Disability Demographics and Statistics, Ithaca, NY, www.disabilitystatistics.org. Accessed 20 February 2014

Organisation for Economic Co-operation and Development (2010) Sickness, Disability, and Work: Breaking the Barriers-A Synthesis of Findings Across OECD Countries. Organisation for Economic Co-operation and Development, Paris

Ruffing KA (2014) How Much of the Growth in Disability Insurance Stems from Demographic Changes? Center on Budget and Policy Priorities. Washington, DC

Social Security and Medicare Boards of Trustees (2013) A Summary of the 2013 Annual Reports: Social Security and Medicare Boards of Trustees. Social Security Administration, Baltimore, MD

Stapleton DC (2011) Bending the Employment, Income, and Cost Curves for People With Disabilities 11-01. Center for Studying Disability Policy, Washington DC

Stapleton DC, O'Day BL, Livermore GA, Imparato AJ (2006) Dismantling the Poverty Trap: Disability Policy for the 21st Century. Milbank Q 84(4):701-732

Stapleton DC, Mamun A, Page J (2014) Initial impacts of the Ticket to Work program: estimates based on exogenous variation in Ticket mail months. IZA J Labor Policy 3:6 
Ticket to Work and Work Incentives Advisory Panel (2007) Building on the Ticket: A new Paradigm for Investing in Economic Self-Sufficiency for People With Significant Disabilities: Final Report to the President and Congress, Year Eight of the Panel. Ticket to Work and Work Incentives Advisory Panel, Washington DC

United States Department of Labor, Bureau of Labor Statistics (2007) National Compensation Survey: Employee benefits in private industry in the United States (2007) Summary 07-05. US Department of Labor, Washington DC

United States Government Accountability Office (2005) Federal Disability Assistance Wide Array of Programs Needs to be Examined in Light of 21st Century Challenges GAO-05-626. US Government Accountability Office, Washington DC

United States Government Accountability Office (2008) Federal Disability Programs More Strategic Coordination Could Help Overcome Challenges to Needed Transformation. GAO-08-635. US Government Accountability Office, Washington DC

Weathers RR II, Wittenburg DC (2009) Employment. In: Houtenville AJ, Weathers RR II, Stapleton DC, Burkhauser RV (eds) Counting Working-age People With Disabilities: What Current Data Tell us and Options for Improvement. The Upjohn Institute for Employment Research, Kalamazoo, MI, pp 101-145

Whalen D, Gimm GW, Ireys HT, Gilman BH, Croake S (2011) Demonstration to Maintain Independence and Employment (DMIE), Final Report. Mathematica Policy Research, Washington DC

Wittenburg D, Mann DR, Thompkins A (2013) The disability system and programs to promote employment for people with disabilities. IZA J Labor Policy 2(1):1-25

World Health Organization and the World Bank (2011) World Report on Disability. Switzerland, Geneva

10.1186/2193-9004-3-14

Cite this article as: Livermore et al: Finding alternatives to disability benefit receipt. IZA Journal of Labor Policy $2014,3: 14$

Submit your manuscript to a SpringerOpen ${ }^{\odot}$ journal and benefit from:

- Convenient online submission

- Rigorous peer review

- Immediate publication on acceptance

- Open access: articles freely available online

- High visibility within the field

- Retaining the copyright to your article

Submit your next manuscript at $\boldsymbol{\nabla}$ springeropen.com 